\title{
Compressive strength parallel to the fiber of spruce with high moisture content
}

\author{
Simon Aicher ${ }^{1} \cdot$ Gordian Stapf $^{1}$
}

Received: 25 March 2015/Published online: 5 February 2016

(c) The Author(s) 2016. This article is published with open access at Springerlink.com

\begin{abstract}
The research aimed to derive substantiated reduction factors for compressive strength and modulus of elasticity parallel to the fiber for structural sized spruce and fir (round) wood with moisture contents at and beyond fiber saturation. Such values, which at present are not given in Eurocodes 5 and 7, are essential in order to perform a reliable design of water/soil immersed piles as well as structural assessment of piles in embankments and foundations of historic, cultural heritage buildings and bridges. The experimental investigations, preceded by a comprehensive literature evaluation, comprised a total of 17 pairs of matched structural sized spruce (Picea abies) pile specimens with mid-length diameters of about $200 \mathrm{~mm}$, with each pair being cut successively from individual logs. From each pair, one specimen was tested in the dry state $(\mathrm{MC}=12 \%)$, and the other in the wet/green state $\left(\mathrm{MC}_{\text {mean }}=90 \%\right)$ according to EN 408 (2010). Further, for calibration purposes, matched small clear specimens with two different aspect ratios were sampled close to the sections from which the structural sized piles were cut. At the mean strength level, the pile compression tests parallel to the fiber gave a moisture reduction factor of $k_{\text {moist,green,mean }}=0.57$, conforming well with the condensed result $(0.54)$ of the literature evaluation on clear wood data, whereas the conducted matched clear wood reference tests gave a $15 \%$ lower reduction factor. The moisture reduction at the $5 \%$ quantile level of the pile compressive strength $k_{\text {moist, green }, 05}=0.65$ was less expressed, and $30 \%$ lower than that obtained for the small clear
\end{abstract}

Simon Aicher

simon.aicher@mpa.uni-stuttgart.de

1 Department of Timber Constructions, Materials Testing Institute University of Stuttgart, Pfaffenwaldring 4 B, 70569 Stuttgart, Germany specimens. The moisture modification factor for the modulus of elasticity in compression parallel to fiber from dry to green state was found to be 0.89 for the pile specimens, which conforms closely to literature data on small clear specimens. Based on the experimental results for the moisture reduction and the present implicit provisions of EC 5 on duration of load, a modification factor $k_{\text {mod }}=0.65 \times$ $0.6=0.4$ is proposed for structural sized spruce/fir piles as well as sawn lumber subjected to permanent load in the water saturated state.

\section{Introduction}

Compressive strength represents the strength property of wood which is most affected by moisture content and hence has to be considered more than in the case of other strengths. In modern timber construction the most important practice relevant moisture conditions are in the range of 6 to $20 \%$. This covers the climate service classes (SC) 1 and 2 , specified equally on the European (CEN) and international (ISO) levels (DIN EN 1995-1-1 2010; ISO 20152-1 2010). SC 1 relates roughly to heated indoor conditions and SC 2 to ventilated, sheltered outdoor conditions. In SC 3, which relates to structures which are fully exposed to weather or subjected to longer lasting, very high (>85\%) relative humidities, the average moisture typically does not exceed 22 to $26 \%$ but can reach beyond fiber saturation in specific cases.

Wood was used in past constructions extensively as timber piles in fully water saturated applications. The soil and water submerged wooden piles still form the bases of many historic buildings and cultural monuments worldwide. In Europe, such historic wooden foundations are widespread, especially in the Netherlands, Italy and in 
Germany. In structural building conservation and renovation, an often occurring task consists in the assessment of the load carrying compression capacity of (historic) water saturated piles. Further design situations for piles with water contact are marinas and embankments.

Today's European material and design standards do not cover strength and stiffness values of round wood or sawn lumber at fiber saturation level or above. On the national level, the Netherlands have standardized quality requirements for soil and water immersed piles (NEN 5491 1999) and design values for wet piles as well (NEN-EN 1995-1-1 NB 2011). The former German timber design code (DIN 1052-1 1988) contained provisions on strength depreciation of fully water immersed timber and, on the other hand on strength increases for round wood as compared to sawn timber with rectangular cross-sections. The lack of acknowledged design provisions and data on wet timber pile strength in conjunction with a structural safety assessment of a $140 \mathrm{~m}$ span historic stone bridge over the Neckar river in Southern Germany, founded on spruce piles, gave rise to the presented investigation.

The paper aims to provide substantiated information on compressive strength and stiffness parallel to the fiber at different dimensions of European spruce (Picea abies) wood in the wet or green state, i.e. covering the moisture content at and beyond fiber saturation. It is reported on coherent tests and evaluations with small defect free (clear) cubic and full-sized round wood pile specimens.

\section{Literature review on relationship of compressive strength and wood moisture content}

Investigations into the moisture-strength relationship of wood have been one of the major research efforts since the use of wood in civil and aircraft engineering. Hereby, as indicated in the introduction, the main research interest focused on the effect of moisture in the hygroscopic range, below about $22 \%$ moisture content. A lesser number of primarily older studies cover the whole wood moisture content range from oven-dry material $(u=0 \%)$ to high degrees of moisture content at and above fiber saturation (30 to $80 \%$ ). The technical term-(wood) fiber saturation-is understood as the water content where in the absence of any free water in the cell lumina, the cell walls are saturated with chemically and physically bound water. Fibre saturation is not a discrete point, but rather a moisture range which may vary considerably depending on species, sap- and heartwood, age, local soil and moisture conditions (Glass and Zelinka 2010). The fiber saturation range of spruce and fir stretches from 30 to $34 \%$ (Kollmann 1955).

It is state of the art to assume that strength and stiffness properties do not change any more beyond fiber saturation, i.e. are independent of any free water in the cell lumina. Although this assumption holds true for most mechanical properties, literature results (see below) show that in case of compression parallel and perpendicular to fiber direction there is still some quantitatively non-negligible strength decreasing effect up to moisture contents of about $u=50 \%$. According to a literature review, the underlying reason for the further strength decrease is unknown. Here, in line with textbooks (Glass and Zelinka 2010) and design codes, the transition from the hygroscopic vs. the water saturated state of wood, also termed green state, is assumed in a rough simplification as a discrete point at $30 \%$ moisture content, marking the lower bound for spruce/fir. As evident from values given below, a further strength degradation of about $7 \%$ occurs between $u=30 \%$ and $u=35 \%$, roughly marking the upper fiber saturation limit of spruce/fir species. Between 35 to $50 \%$ a further strength decrease of about 5 to $7 \%$ can be obtained.

\subsection{Present code provisions}

\subsubsection{European timber design code}

The European timber design code, DIN EN 1995-1-1 (2010) or also known as EC 5, specifies the effect of moisture on the strength of timber construction components such as solid wood or glulam via an integral modification factor, $k_{m o d}$, which simultaneously accounts for the duration of load (DOL), i.e. the accumulated time of loading effect on strength. The modification factor is given for the three service classes 1, 2 and 3, mentioned before, and five load duration classes ranging from short term (less than a week) to permanent loading (more than 10 years). The $k_{m o d}$-factors are further specified as being equal for service classes 1 and 2, which is questionable in some cases. For reasons of simplicity, no differentiation has been made within the $k_{m o d}$-values regarding different strength properties, e.g. for tension or compressive strength. Within the frame of the above described concept it is generally understood that the crude smearing of the moisture effects and of the effects of loading time leads to considerable inaccuracies, especially when compression loading of timber is considered. The integral $k_{\text {mod }}$-factor in EC 5 can be roughly split by a product assumption into the separate impacts of moisture and loading time, respectively

$k_{\text {mod }}=k_{\text {moist }} \cdot k_{\text {time }}$.

Such a product assumption is also implemented in the North American and New Zealand timber design codes (ANSI/AWC NDS 2015; CSA O86-09 2009; NZS 3603 1993). By comparison of the EC 5- $k_{m o d}$ factors of service classes 1 and 2 with those of service class 3 , one obtains via Eq. (1) throughout the respective different load 
duration classes $\left(k_{\text {time }}=\right.$ const. $)$ a rather constant moisture strength reduction value of $k_{\text {moist }}=0.8$ meant to hold for any wood moisture levels above 18 to $20 \%$, considered to be the maximum in SC 2 conditions. It is meanwhile a widely acknowledged fact and is reflected in recent publications (Frese et al. 2011) as well as in technical specifications for hardwood glulams (Austrian Institute of Construction Engineering (OiB) 2013a, b), that a strength reduction in SC 2 conditions is necessary, especially in the case of compressive strength parallel to the fiber. Further, it is well understood that in the case of compression parallel to the fiber $k_{\text {moist }}=0.8$ is too high, i.e. delivers too small of a strength reduction for moisture states close to and beyond fiber saturation. This issue which is especially relevant for the design of water saturated piles is presently not addressed in EC 5 at all.

In contrast, the Dutch national appendix to EC 5, NENEN 1995-1-1 NB (2011), specifies design values for the compressive strength parallel to the fiber

$f_{c, 0, d}=f_{c, 0, k} \cdot k_{\text {mod }} / \gamma_{M}$

for "timber poles used for foundation purposes", i.e. for wet/water saturated conditions, being $f_{c, 0, d}=11.5$ and 9.8 MPa respective to different load combinations [long and permanent, according to NEN-EN 1990+A1+A1/C2 (2011)]. Since only the design values are given, it is not apparent what values were used for the characteristic (5\% quantile) strength $f_{c, 0, k}$, modification factor $k_{\text {mod }}$ and partial safety factor $\gamma_{M}$. Background information on the Dutch design values is provided in Sect. 3.2.

\subsubsection{US code provisions}

The National Design Specification (NDS) for Wood Construction (ANSI/AWC NDS 2015) refers to ASTM D2899-12 (2012), which converts strengths and stiffnesses related to clear wood specimens to reference design values of piles and poles that are graded per ASTM D3200-74 (Reapproved 2012) (2012). The clear wood material properties in ASTM D2555-06 (Reapproved 2011) (2011), for 33 softwood species grown in the USA are given with mean values and standard deviations for the moist, i.e. "unseasoned" $(u>30 \%=$ green $)$ state. The compressive strengths parallel to the fiber for spruce and fir wood species, range from $f_{c, 0,50}=15.0 \mathrm{MPa}$ for Engelman Spruce to $f_{c, 0,50}=19.6 \mathrm{MPa}$ for Black Spruce.

In addition to the compressive strength and MOE properties in the green state, the ratios of green to dry $(u=12 \%) \quad$ clear wood properties $\frac{f_{c, 0,0 \text { reen,cleawood }}}{f_{c, 0, d r y, \text { clearwood }}}$ and $\frac{E_{0, \text { gren,clearwood }}}{E_{0, \text { dry,clearwood }}}$ are given. For spruce and fir species grown in the United States, the ratios of compressive strengths vary from 0.47 for Subalpine Fir to 0.56 for Grand Fir. The MOE reduction factors-pointedly higher-span from 0.78 for White Fir to 0.86 equally for Balsam Fir and Black Spruce.

The conversion of mean values $f_{c, 0,50}$ and standard deviations $s$ of small clear wood to allowable stress values of full sized piles or poles $F_{c}$ is handled in ASTM D289912 (2012) via four adjustment factors

$$
F_{c}=\left(f_{c, 0,50}-k \cdot s\right)\left(C_{c d o l} C_{h v} C_{d} C_{g}\right)
$$

where

$k=1.645 \quad 5 \%$-quantile of the normal distribution $C_{c d o l} \quad$ for duration of load (10 years) and safety

$C_{h v} \quad$ for height and for reduced variability

$C_{d} \quad$ for density (only Douglas fir and Pine)

$C_{g} \quad$ for grade characteristics

In the case of compression parallel to the fiber with $C_{c d o l}=1 / 1.9=0.53, \quad C_{h v}=0.91, \quad C_{d}=1$ (spruce $/$ fir $)$, $C_{g}=0.93$ and $f_{c, 0,05}=f_{c, 0,50}-k \cdot s$, the allowable stress becomes

$F_{c}=f_{c, 0,05} \cdot 0.45$.

With regard to Eqs. $(3,4)$, it is important to state that the impact of moisture (wet to dry) is transposed unchangedly from the mean small clear specimen level to the $5 \%$ quantile level of small clear and further to the $5 \%$ quantile level of the structural sized specimens/piles. The exclusive difference between structural sized green piles and green small clear specimens on the $5 \%$ quantile level is specified by the ratio

$\frac{f_{c, 0, \text { green }, \text { pile }, 05}}{f_{c, 0, \text { green, }, \text { clearwood }, 05}}=C_{h v} \cdot C_{g}=0.85$.

The MOEs for full sized dry and green piles are derived from the clear wood MOE by means of three adjustment factors from which only factor $C_{h}$ specifying the impact of tree height accounts for the difference between clear wood and full sized lumber:

$\frac{E_{0, \text { green,pile }}}{E_{0, \text { green,clearwood }}}=C_{h}=0.96$.

\section{Review of published tests}

\subsection{Small and medium sized clear specimens}

Figure 1 shows experimental relationships of compressive strength parallel to the fiber versus wood moisture content of European spruce and fir wood derived from literature. The moisture dependant strength values are given normalized to the strengths at moisture content $u=12 \%$ (compare Eq. 8b). The majority of the curves is based on pioneering investigations performed in the middle of the 20th century (Roš 1936; Kühne et al. 1955; Kollmann 
Fig. 1 Curves for moisture modification factor for compression strength parallel to the fiber of European spruce (Picea abies) and fir (Abies alba) derived from fits to literature data and equations (Roš 1936; Kühne et al. 1955; Kollmann 1955; Glos 1978)

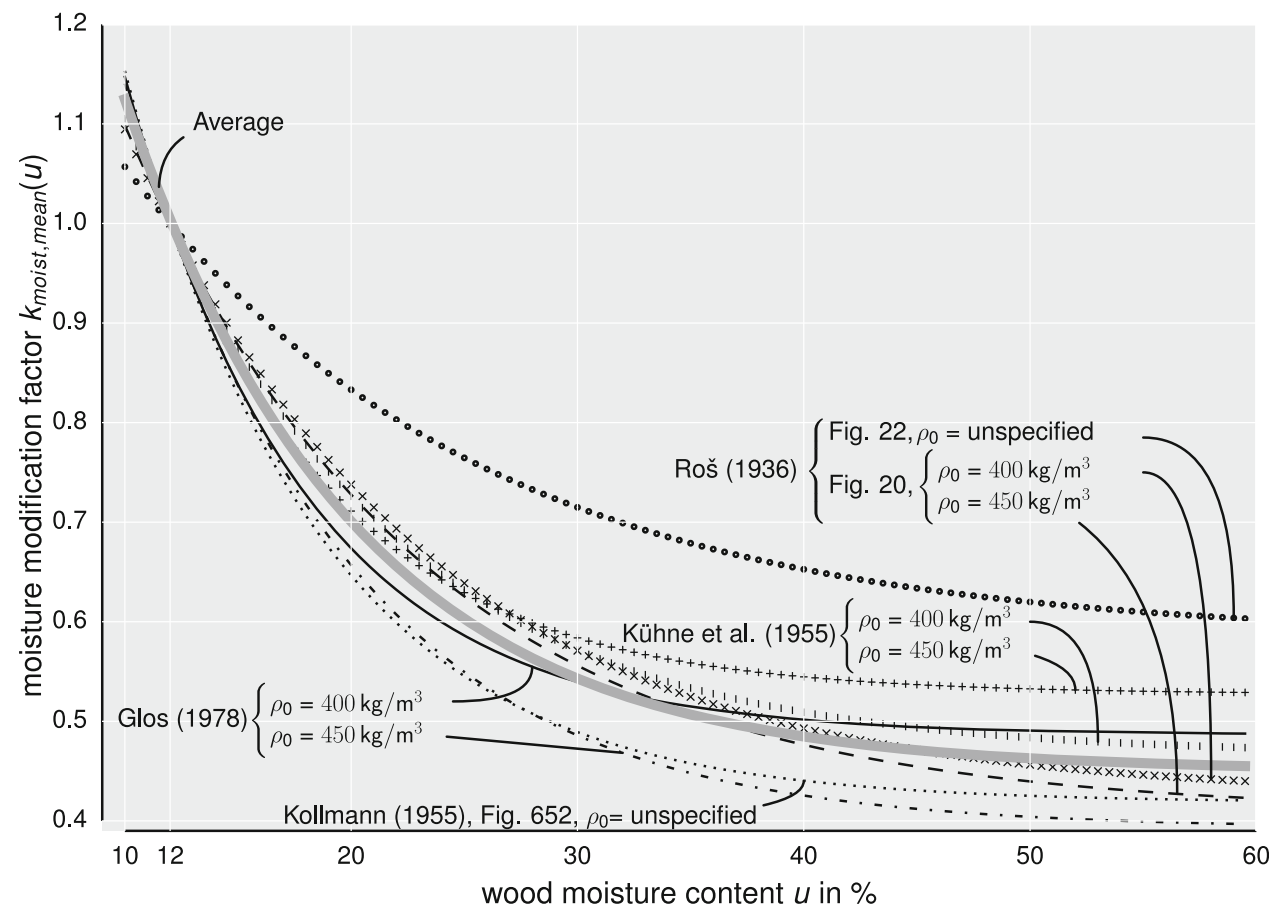

1955), where the effect of wood density and specimen size on strength and stiffness has not been considered as relevant as it is today and hence had not been reported throughout. Although the specimen dimensions are not specified explicitly in all above cited references, it can be stated that the cross-sectional dimensions were in the range of 20 to $40 \mathrm{~mm}$ and the specimen height parallel to wood fiber and load direction was about 2 to 4 times the smaller cross-sectional edge length. The specified graphs are mostly based on figures given in the references; for details see legend of Fig. 1 and Table 1.

Further, Fig. 1 contains curves from an analytical equation derived by Glos (1978) within the presumably most comprehensive study on the constitutive behaviour of spruce in compression parallel to the fiber. The investigations included the influence of wood density, moisture content, knot area ratio and compression wood percentage on strength, modulus of elasticity and stress-strain law in general. The tests were performed with slabs from boards with a thickness $t$ of prevailingly $(>80 \%)$ about $30 \mathrm{~mm}$, widths in the range of 70 to $220 \mathrm{~mm}$ (predominantly 150 $\mathrm{mm}$ ) and constant height of $h=180 \mathrm{~mm}$ in direction of load and fiber. Hence, the specimen aspect ratio $h / t=6$ conformed to EN 408 (2010); MOE measurement was performed within a gauge length of $4.6 t$. The investigations with well over 900 specimens resulted i.a. in a multiple regression equation for mean compression strength, here given in truncated format as knot area ratio $a$ and compression wood percentage $d$ are almost irrelevant in this context:

$$
\begin{aligned}
& f_{c, 0, \text { mean }}\left(u, \rho_{0}, a=d=0\right)= \\
& \quad-1.9-2.23 u+0.224 \rho_{0}+0.109 u^{2}-0.00741 u \cdot \rho_{0}
\end{aligned}
$$

where $u$ is moisture content in $\%$ and $\rho_{0}$ is density in ovendry state in $\mathrm{kg} / \mathrm{m}^{3}$. The permissible density range of Eq. (7) is $330 \mathrm{~kg} / \mathrm{m}^{3} \leq \rho_{0} \leq 600 \mathrm{~kg} / \mathrm{m}^{3}$ which covers most of the realistic densities of European spruce. Regarding applicable moisture contents, the validity of Eq. 7 is, strictly taken, bound to the range $6 \% \leq u \leq 22 \%$; nevertheless a small extrapolation regarding higher moistures seems justified. Although Eq. (7), as revealed, cannot be used explicitly for assessment of compressive strength parallel to the fiber in the green state, it allows for a good assessment of the shapes and levels of the other curves in the hygroscopic moisture range given in Fig. 1.

In order to enable a quantitative evaluation of the relevant data published in literature in some instances exclusively in a graphical manner, the data points were approximated by analytical equations. In the attempt to fit all referenced data and equations as well as possible with one simple expression, it was found that the best approximation was given by the exponential function

$f_{c, 0, \text { mean }}(u)=A \cdot e^{-B u}+C$.

Based on the absolute strength curves $f_{c, 0 \text { mean }}(u)$ according to Eq. (8a), which also implicitly includes the effect of density, the relative influence of moisture on mean compressive strength vs. reference conditions at 
$u=12 \%$, termed moisture modification factor, is defined as

$$
k_{\text {moist }, \text { mean }}(u)=\frac{f_{c, 0, \text { mean }}(u)}{f_{c, 0, \text { mean }, \text { dry }}}=a \cdot e^{-b u}+c .
$$

The parameters of Eqs. (8a, b) derived by least square approximation of the cited literature sources are given in Table 1 ; additionally $k_{\text {moist,mean }}(u)$ values according to Eq. $8 \mathrm{~b}$ are listed for discrete moisture levels of $u=18,24$, 30 and $50 \%$ for the respective literature data bases. Disregarding the specific data set given by Roš (1936), there Fig. 22 with unspecified $\rho_{0}$, a best square fit by Eq. (8b) to all literature references gave the parameters $a=1.89$, $b=0.1$ and $c=0.45$, whereby $u$ is in $\%$.

Eq. (8b) then delivers for the water saturated, green state $(u>30 \%=$ green, $u=12 \%=$ dry)

$$
\begin{aligned}
k_{\text {moist,mean,green }} & =\frac{f_{c, 0, \text { mean }, \text { green }}}{f_{c, 0, \text { mean }, \text { dry }}} \\
& =1.89 \cdot e^{-0.1 \cdot 30}+0.45 \\
& =0.54 .
\end{aligned}
$$

Regarding the individual curves, $k_{\text {moist,mean,green }}$ lies in the range from about 0.5 to 0.6 . Strictly speaking, the ratio in Eq. (9) applies to the density range of $\rho_{0}=400$ to $450 \mathrm{~kg} /$ $\mathrm{m}^{3}$, corresponding to $\rho_{12}=420$ to $480 \mathrm{~kg} / \mathrm{m}^{3}$. Whether the specified moisture reduction factors determined from defect free clear wood specimens as well as from moisturewise extrapolated strengths of medium sized quasi clear specimens can be used for specimens of structural dimensions and for water saturated round wood is unclear. This applies also to the question of to what extent the level of $k_{\text {moist,green }}$ according to Eq. (9) is also valid for the design relevant $5 \%$ quantile strength level.

\subsection{Full sized pile specimens}

Results of comprehensive compressive strength tests with 57 water-saturated European spruce pile segments, investigated at the Dutch Houtinstituut (Timber Institute) TNO, are reported in Buiten and Rijsdijk (1982). The tests did not comprise matched dry pile specimens, which would allow a

\begin{tabular}{|c|c|c|c|c|c|c|c|c|c|c|c|c|c|}
\hline \multicolumn{3}{|c|}{ Reference details $^{\mathrm{a}}$} & \multicolumn{6}{|c|}{ Parameters of Eqs. $(8 \mathrm{a}, \mathrm{b})$} & \multirow{2}{*}{$\begin{array}{l}\text { Reference } \\
\text { strength } \\
f_{c, 0, d r y} \\
\mathrm{MPa}\end{array}$} & \multicolumn{4}{|c|}{$\begin{array}{l}\text { Moisture modification factors } \\
k_{\text {moist,mean,green }}(u)\end{array}$} \\
\hline $\begin{array}{l}\text { Species } \\
-\end{array}$ & $\begin{array}{l}\text { Moisture } \\
\%\end{array}$ & $\begin{array}{l}\text { Density } \\
\mathrm{kg} / \mathrm{m}^{3}\end{array}$ & $\begin{array}{l}\rho_{0} \\
\mathrm{~kg} / \mathrm{m}^{3}\end{array}$ & $\begin{array}{l}A \\
\mathrm{MPa}\end{array}$ & $\begin{array}{l}C \\
\mathrm{MPa}\end{array}$ & $\begin{array}{l}B=b \\
\%\end{array}$ & $\begin{array}{l}a \\
-\end{array}$ & $\begin{array}{l}c \\
-\end{array}$ & & $\begin{array}{l}18 \% \\
-\end{array}$ & $\begin{array}{l}24 \% \\
-\end{array}$ & $\begin{array}{l}30 \% \\
-\end{array}$ & $\begin{array}{l}50 \% \\
-\end{array}$ \\
\hline \multicolumn{14}{|c|}{ Roš (1936), Fig. 20.} \\
\hline $\mathrm{sp}^{\mathrm{b}}$ & $0 ; 18 ;>30$ & $300-500$ & 400 & 54.5 & 16.1 & 0.076 & 1.342 & 0.423 & 38.1 & 0.79 & 0.66 & 0.57 & 0.46 \\
\hline$w f^{c}$ & $0 ; 18 ;>30$ & $300-500$ & 450 & 65.9 & 18.0 & 0.077 & 1.492 & 0.408 & 44.2 & 0.78 & 0.64 & 0.56 & 0.44 \\
\hline \multicolumn{14}{|c|}{ Roš (1936)), Fig. 22.} \\
\hline $\mathrm{sp}^{\mathrm{b}}$ & $0 ; 18 ;>30$ & $300-500$ & $-{ }^{\mathrm{d}}$ & 29.6 & 19.2 & 0.064 & 0.898 & 0.583 & 33.0 & 0.87 & 0.78 & 0.71 & 0.62 \\
\hline \multicolumn{14}{|c|}{ Kollmann (1955), Fig. 652.} \\
\hline $\mathrm{sp}^{\mathrm{b}}$ & $0-100$ & $-{ }^{\mathrm{d}}$ & $-{ }^{\mathrm{d}}$ & 111.4 & 19.7 & 0.117 & 2.367 & 0.419 & 47.1 & 0.71 & 0.56 & 0.49 & 0.43 \\
\hline \multicolumn{14}{|c|}{ Kühne et al. (1955), Fig. 9a. } \\
\hline $\mathrm{sp}^{\mathrm{b}}$ & $0-160$ & $400-450$ & 400 & 61.1 & 18.1 & 0.090 & 1.571 & 0.465 & 38.9 & 0.78 & 0.65 & 0.57 & 0.48 \\
\hline$w f^{c}$ & $0-160$ & $400-450$ & 450 & 88.6 & 24.0 & 0.118 & 1.948 & 0.528 & 45.5 & 0.76 & 0.64 & 0.58 & 0.53 \\
\hline \multicolumn{14}{|c|}{ Glos (1978), Eq. (5.28), here (Eq. 7). } \\
\hline $\mathrm{sp}^{\mathrm{b}, \mathrm{e}}$ & $6-22$ & $330-660$ & 400 & 95.0 & 19.8 & 0.126 & 2.329 & 0.485 & 40.8 & 0.73 & $0.60^{\mathrm{f}}$ & $0.54^{\mathrm{g}}$ & $0.49^{\mathrm{g}}$ \\
\hline $\mathrm{sp}^{\mathrm{b}, \mathrm{e}}$ & $6-22$ & $330-660$ & 450 & 100.7 & 18.7 & 0.104 & 2.116 & 0.393 & 47.6 & 0.72 & $0.57^{\mathrm{f}}$ & $0.49^{\mathrm{g}}$ & $0.40^{\mathrm{g}}$ \\
\hline Average $^{\mathrm{h}}$ & - & - & 425 & 75.9 & 19.2 & 0.097 & 1.758 & 0.463 & 41.9 & 0.77 & 0.64 & 0.56 & 0.48 \\
\hline
\end{tabular}
direct assessment of the moisture influence. The diameter

Table 1 Parameters of fits and the relative strength values at different moisture contents normalized to strength at reference moisture content $(\mathrm{MC})=12 \%$

${ }^{a}$ All referenced Figs. and Eqs. refer to $x_{\text {mean }}$ curves/data

b Spruce (Picea abies)

c White fir (Abies alba)

d Not specified

${ }^{\mathrm{e}}$ Eq. (5.28) accounts additionally for knot area ratios $a=0-45 \%$ and compression wood percentage $d=0-45 \%$; here $a=d=0$ evaluated

${ }^{\mathrm{f}}$ Marginally outside specified validity range

g Outside specified validity range

${ }^{\text {h }}$ Excluding Roš (1936), Fig. 22 
(without bark) of the spruce specimens ranged from 265 to $540 \mathrm{~mm}$, with an average of $460 \mathrm{~mm}$. The length was throughout $900 \mathrm{~mm}$ resulting in a very stout specimen with an average slenderness of 2.0. The moisture content of the spruce specimens as evaluated from the report ranged from 60 to $180 \%$, and was therefor throughout (average: $110 \%$ ) well beyond fiber saturation.

The wood/pile quality was assessed by measurement of maximum knot diameters, and knot area ratio according to NEN 5491 (1999), i.e. sum of knots (largest diameter) over a length of $150 \mathrm{~mm}$ divided by the circumference. The maximum knot diameters were between 5 and $60 \mathrm{~mm}$ and the knot area ratio was in the range from 0.2 to 0.6 . As a considerable number of specimens did not fully comply with the pile grade requirements specified in NEN 5491 (1999) where single knot diameter is the most relevant criterion, the strength evaluation was subdivided into two samples comprising (1) all specimens and (2) all standard conforming specimens. However, the strength differences between the full sample and the respective subsample were revealingly marginal. Hence, no correlation between the growth characteristics and the strength values was found.

The mean water saturated compressive strength (total sample $=57$ ) thus became

$f_{c, 0, \text { mean,green }}=20.0 \pm 2.2 \mathrm{MPa}(\mathrm{COV}=11 \%)$.

A characteristic wet (green) compressive strength value was then derived as (van de Kuilen 1994) $f_{c, 0, k, \text { green }}=$ $x_{\text {mean }}-t_{\text {student }} s \sqrt{1+n^{-1}}=20.0-1.7 \cdot 2.2=16.3 \mathrm{MPa}$. An evaluation according to EN 14358 (2007) would result in a very similar value of $16.0 \mathrm{MPa}$.

A direct conclusion on the moisture impact cannot be drawn from the test results. Nevertheless, the specified characteristic green pile strength value has been used to derive pile design compressive strength values according to the EC 5 format (Eq. 2). In order to derive a dry single pile compressive strength value, a multiplication factor of 1.21 was applied (van de Kuilen 1994), resulting in $f_{c, 0, k, d r y}=19.8 \mathrm{MPa}$. The former Dutch single pile wet/ green design compressive strength value of $f_{c, 0, d}=9.9 \mathrm{MPa}$ (NEN 6760 2008) was then derived by applying $k_{\text {mod }}=0.6$ and $\gamma_{M}=1.2$.

As mentioned previously the validity of the moisture modification factor of $k_{\text {moist, green }}=1 / 1.21=0.82$ should be questioned, especially if this factor was indiscriminately applied to adjust dry compression strength parallel to grain values to wet values. In the van de Kuilen (1994) study, the reversed adjustment from wet to dry compression strength parallel to grain values yielded an overly conservative dry characteristic strength.

This is evident from the absolute level of the characteristic dry pile strength, which is lower than the characteristic compressive strength value $f_{c, 0, k}=21 \mathrm{MPa}$ for sawn coniferous lumber of strength class C24 which assumingly was reached in the reported test sample.

The present Dutch design compression value for wet/ green piles of $f_{c, 0, d}=9.8 \mathrm{MPa}$ (NEN-EN 1995-1-1 NB 2011) for load combination permanent, which is slightly lower than the pre-Eurocode value of NEN 6760 (2008), was validated (Jorissen 2007) by use of a calculated characteristic wet pile compressive strength value of $f_{c, 0, k, \text { green }}=15.4 \mathrm{MPa}$, which is slightly lower than the reported test value of $16.3 \mathrm{MPa}$. Hereby, the wet strength value was derived from the dry pile value by multiplication with factor $k_{\text {moist }}=0.6$ derived from Eq. (7).

The above illustration of the different approaches on compressive strength design values of water saturated piles, irrespective of the similar final results, reveals the obvious necessity to resolve the issue of a $k_{\text {moist, green }}$ modification factor applicable to structural sized timber including piles.

\section{Materials, specimens, and test program}

The conducted test program was designed to establish a consistent verification of the factor $k_{\text {moist,green }}$ for small clear and full-scale round wood piles, at the mean and $5 \%$ quantile level. In order to reveal the effect of moisture on strength between the $12 \%$ moisture content and the green state, matched specimens (cut in a specific manner from individual $\log$ s, see below) were used at the small and the full-scale pile level.

\subsection{Log material}

The test material comprised $2 \times 21 \mathrm{log} / \mathrm{stem}$-segments from individual trees which were purchased from a selected forest stand in Southern Germany, close to Stuttgart. The grade of the log-segments conformed to NEN 5491 (1999) with maximum knot diameters of 19 to $42 \mathrm{~mm}$ and knot area ratios of 0.11 to 0.31 , hereby also conforming to Güteklasse II according to DIN 4074-2 (1958) and to Güteklasse B according to RVR (2015). The log segments, hereby known as "logs" only had a length of $3.5 \mathrm{~m}$ each and the average bottom and top diameters were $d_{\text {bottom,mean }}=230 \mathrm{~mm}$ and $d_{\text {top,mean }}=185 \mathrm{~mm}$, respectively. The felling of the trees had been undertaken one month prior to purchase; between felling and delivery to the Institute, the trees were stored unsheltered at the sawmill. The $\operatorname{logs}$ were received in the green state. After grading, 4 pairs were excluded due to excessive knots/ bow, so $2 \times 17$ pairs remained for full sized compression testing. One of the rejected $\log s$ was used for detailed moisture measurements. 
Fig. 2 Cutting scheme and dimensions (side view) of $\log s$ and specimens for full scale pile and small scale clear wood tests (dimensions in $\mathrm{mm}$ )

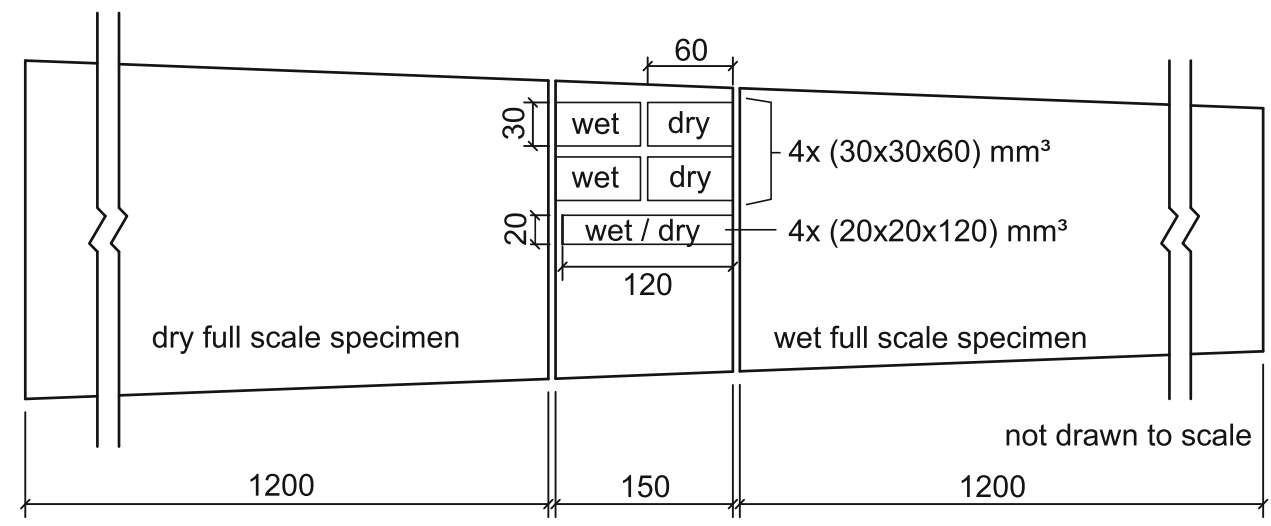

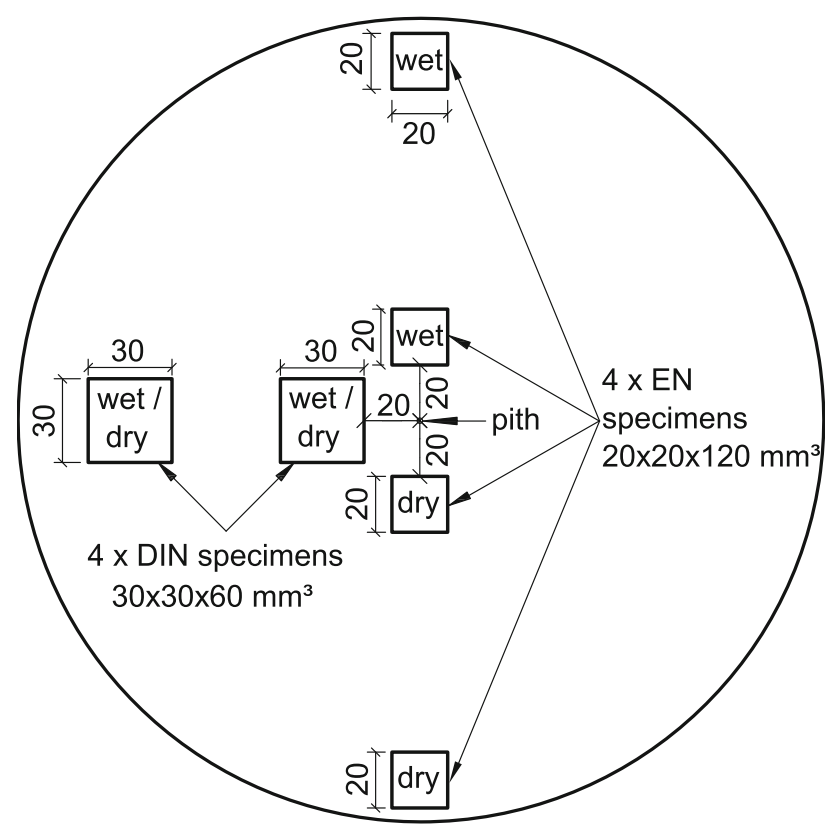

Fig. 3 Cutting scheme and cross-sectional dimensions of matched small scale clear wood specimens (dimensions in $\mathrm{mm}$ )

From each log, two structural sized pile specimens with equal lengths of $1.2 \mathrm{~m}$ were cut almost successively, leaving only a narrow slice of about $150 \mathrm{~mm}$ in between. One of each matched, round wood specimens from each $\log$ was tested in wet, water-saturated state (see below) and the other in dry state. From the intermediate log slices, matched small clear specimens for wet and dry testing were taken. Figures 2 and 3 reveal the cutting scheme of the delivered logs into structural sized pile specimens and the cutting scheme of the matched small scale specimens.

\subsection{Pile specimens}

The aspect ratio of the $2 \times 17$ full-scale pile specimens tested in compression parallel to the fiber was chosen according to the respective provisions in the European test standard for structural sized lumber, EN 408 (2010). The length of the pile specimens was nominally 6 times the smallest diameter of the employed conical log sections. The diameters of the dry and wet pile specimens varied in the range of 170 to $255 \mathrm{~mm}$ at the bottom end and 162 to 241 $\mathrm{mm}$ at the top end. The average mid-length diameters of the dry and wet tested specimens were 213 and $197 \mathrm{~mm}$, respectively (see Table 4). The specimens tested in the wet state were taken throughout from the thinner, tree top-oriented part of the stem section. This selection procedure, slightly violating the otherwise rigorously pursued matching procedures, is owed to the limited diameter of the pressurevacuum-vessel that was used to increase the moisture of the wet logs (see below) before they were tested.

\subsection{Small clear specimens}

Two different geometries and slightly different sizes were investigated with regard to effect of moisture on strength. One set of small clear specimens conformed to the aspect ratio provisions given in EN 408 (2010) where the crosssectional dimensions were $20 \mathrm{~mm} \times 20 \mathrm{~mm}$ perpendicular to the fiber direction and the length was $120 \mathrm{~mm}$. The other set of specimens conformed to the previous German standard DIN 52185 (1976) for small clear specimens where the much smaller aspect ratio of 2 resulted from a crosssection of $30 \mathrm{~mm} \times 30 \mathrm{~mm}$ and a length of $60 \mathrm{~mm}$.

The specimens were cut as shown schematically in Figs. 2 and 3 from each intermediate log slice in such a manner that matching was best possible between dry and wet specimens of each specific specimen type (DIN 52185 or EN 408). Further, the spatial arrangement of the specimens should allow for the assessment of the effect of the position within the stem cross-section on the moisture strength relationship. In order to enable this, one group of the specimens was cut from the heart wood area at a distance of $20 \mathrm{~mm}$ from the pith and the other group was cut from the sapwood region with a distance of $20 \mathrm{~mm}$ from the periphery. The matching of the dry and wet specimens 
according to EN 408 and DIN 52185 was performed as shown schematically in Figs. 2 and 3. Due to the shorter length of the DIN specimens $(60 \mathrm{~mm})$, the matching with regard to effect of moisture was performed by cutting both specimens from one longer stick $(l=125 \mathrm{~mm})$, enabling the highest possible similarity with regard to annual ring orientation within the cross-section. The matching of the longer sized EN 408 specimens with regard to the moisture effect was performed by cutting the specimens at the same radial distances $r_{i}=20 \mathrm{~mm}$ and $r_{a}=D / 2-20 \mathrm{~mm}$ at a circumferential angle distance of $\pi / 2$. The $21 \operatorname{logs}$ together with the applied cutting scheme delivered for each geometry configuration (DIN 52185 and EN 408) 42 dry and 42 wet small clear specimens, whereby $50 \%$ were from the heartwood and sapwood, respectively.

\section{Conditioning and moisture content of specimens}

The conditioning of the specimens with regard to the target moisture conditions was performed as follows. The small specimens used for tests in dry condition (nominal $\mathrm{MC}=12 \%$ ), were stored for 12 weeks at a climate of $20{ }^{\circ} \mathrm{C}$ and $65 \% \mathrm{rh}$, resulting in an average moisture content of $13.9 \pm 0.3 \%$ at test time. The dry pile specimens were first stacked in a climate chamber at $20{ }^{\circ} \mathrm{C}$ and $65 \%$ rh for 25 weeks and subsequently subjected to a dryer (35\% rh) climate in the testing hall for 4 weeks. The pile specimens dried to an average MC of $12.5 \pm 0.8 \%$, determined after testing from slab 5 at mid-length (see below), whereby a moisture gradient of about $4 \%$ along the cross-sectional diameter remained.

The small and the pile specimens tested in wet condition, though having been cut from green stems, were vacuum pressure treated with cold water $\left(10{ }^{\circ} \mathrm{C}\right)$ to obtain a higher degree of moisture uniformity over the cross-section. The water treatment comprised 20 successive cycles whereby each cycle consisted of a vacuum (absolute pressure of $20 \mathrm{kPa}$ ) held for 20 minutes, followed by 35 min of pressure treatment (absolute pressure: $500 \mathrm{kPa}$ ).
This procedure resulted in very uniform moisture contents for the small specimens, with an average value of $192 \%$ with variations of $\pm 20 \%$ over cross-sectional dimensions.

In the case of the pile specimens however, considerable moisture gradients in radial and stem axis direction remained. The gradients in both directions were determined from one spare wet pile specimen (No. 21) used for moisture measurement purposes only. Six cross-sectional slabs, each with a thickness of $30 \mathrm{~mm}$, were cut at different positions along the $\log$ axis and then each slab was subdivided into cubic specimens $\mathrm{A}$ to $\mathrm{E}$ arranged symmetrically to the pith in the slab (Fig. 4). Further, from each of the 17 pile specimens tested in wet state, a moisture control slab-then cut into cubic specimens A to E-was taken at mid-length (position of slab 5, Fig. 4) immediately after testing. The moisture content of the slab specimens was determined by the oven dry method.

Figure 5 shows the cross-sectional moisture distributions of slabs 1 to 6 along the axis of wet pile No. 21 . Every slab reveals a very pronounced moisture gradient along the cross-sectional diameter. The outer sapwood area specimens A and E show consistently for all slabs moisture values in the range of 190 to $220 \%$. Towards the inner

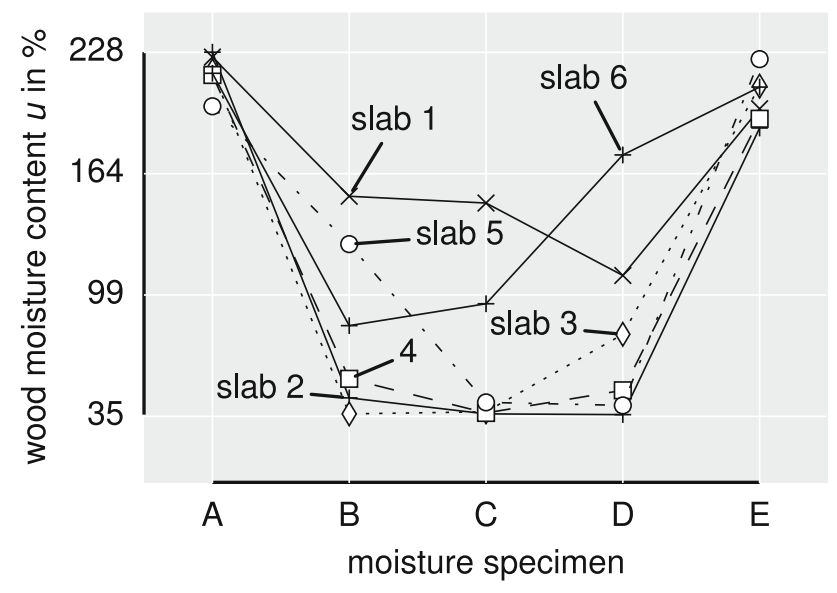

Fig. 5 Cross-sectional moisture distributions of the wet pile specimen No. 21 at different positions (slabs 1-6) along pile axis

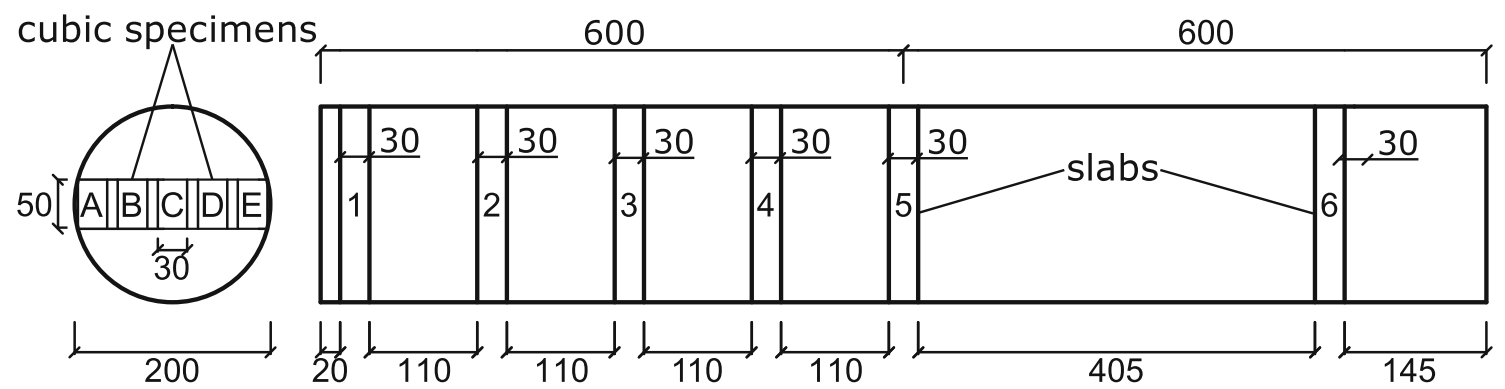

Fig. 4 Cutting scheme of specimens at wet pile specimen No. 21 for determination of moisture gradients along log axis and diameter (dimensions in $\mathrm{mm}$ ) 


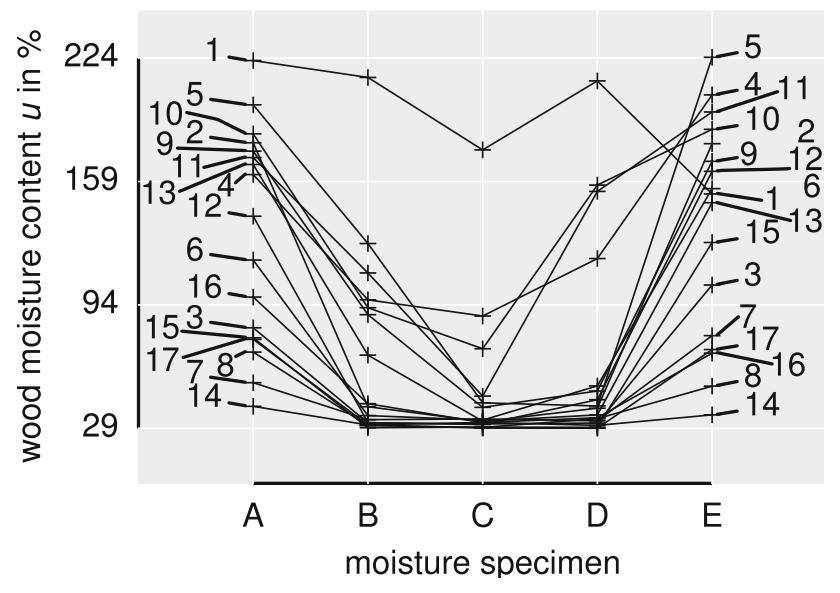

Fig. 6 Cross-sectional moisture distributions at mid-length of all pile specimens tested in wet state

heartwood area, the moisture content decreases significantly, being rather radially symmetric apart from slabs 1 and 6 at the pile ends. In the lengthwise inner part of the $\log$ (slabs 3 to 5), the moisture content of the centroid (pith) specimen $\mathrm{C}$ is roughly $35 \%$ reaching up to $150 \%$ for the end-located slab 1.

Figure 6 presents the cross-sectional moisture distribution of all wet piles as determined from the individual mid-length slabs 5 . Aside from pile No. 1 , which showed a very high moisture content $(u>150 \%)$ throughout the cross-section, a pronounced cross-sectional moisture gradient was seen in all piles similar to that of pile No. 21, depicted in Fig. 5. In the center of the stems, moisture specimens B, C, D, the moisture content was between 29 and $151 \%$ with a median at $34 \%$ (pile No. 1 excluded). More detailed, the medians for both specimens B and D were $38 \%$ whereas at mid-width (specimen C), the median moisture content was $32.5 \%$. For about half of the wet pile specimens, moisture values of at least two adjacent specimens $B$ and $C$ or $C$ and $D$ were in the range of 29 to $34 \%$. The moisture content at the stem periphery, moisture specimens $\mathrm{A}$ and $\mathrm{E}$, was denoted by median and mean values of $144 \%$ and $130 \pm 55 \%$. The three lowest moisture values (in ascending order) were: 36,41 and $51 \%$.

In summary, it can be stated that the minimum moisture content of the pile specimens was in majority along pile length and cross-section beyond the chosen fiber saturation limit of $30 \%$. However, since the saturation level might be higher for some specimens and clear wood tests indicate that compressive strength drops after reaching the upper realistic saturation level of $35 \%$, the obtained strengths of the wet log specimens should be rather higher than lower compared to long-time water submerged piles.

\section{Compression tests parallel to the fiber}

\subsection{Small clear specimens}

Prior to testing, the weights and dimensions were measured to determine the density $\rho_{u}$ at test time. The axial compression tests parallel to the fiber with the small clear specimens following the provisions in EN 408 (2010) and DIN 52185 (1976), were performed displacement-controlled with a constant rate of cross-head motion of $4 \mathrm{~mm} /$ min in a computer controlled electro-mechanical test machine (type: Zwick/Roell Smart.pro $100 \mathrm{kN}$ ). The modulus of elasticity was not measured. The tests were conducted at about $20{ }^{\circ} \mathrm{C}$; relative humidity (rh) was in the range of 40 to $55 \%$. Immediately after testing, all specimens were oven dried for determination of moisture content and densities $\rho_{0}$ and $\rho_{12}$.

\subsection{Pile specimens}

Prior to testing, all dry and wet pile specimens were weighed and measured (circumferences at top, bottom and mid length). The tests were performed with a computer controlled servo-hydraulic test machine (Ernst HPM 1600 ) with a load capacity of $1600 \mathrm{kN}$ in a non climatized environment at a temperature of 18 to $21{ }^{\circ} \mathrm{C}$ and a relative humidity of about $40 \%$. Figure 7 shows the test scheme and Fig. 8 gives views of the realized test set-up. The butt-oriented end of the pile specimens was supported unhinged (flat end condition) by a rigid horizontal steel platform. The small/top end was loaded by the piston of the test machine via an intermediate steel plate connected with a spherically supported compression hinge whose rotation could be blocked by screws (Figs. 7, 8b). According to EN 408, the specimens were loaded with an unblocked upper hinge to a preload level of $0.5 \%$ of $F_{c, 0, \text { max.estimated }}$, after which point the hinge was restrained from further rotation.

For all wet and dry pile specimens, the axial compression displacement was measured over a constant length of $660 \mathrm{~mm}$ in the center section of the specimen length by four LVDTs mounted at circumferential distances of $\pi / 2$ (see Figs. 7, 8a). Depending on the slightly varying log diameters, the displacement measurement length was in the range of about 2.5 to 3 times of the specimen diameter at mid-length.

The tests were performed displacement-controlled in accordance with EN 408 (2010) at a constant piston speed of $20 \mathrm{~mm} / \mathrm{min}$. Failure was obtained within $300 \pm 120 \mathrm{~s}$. 


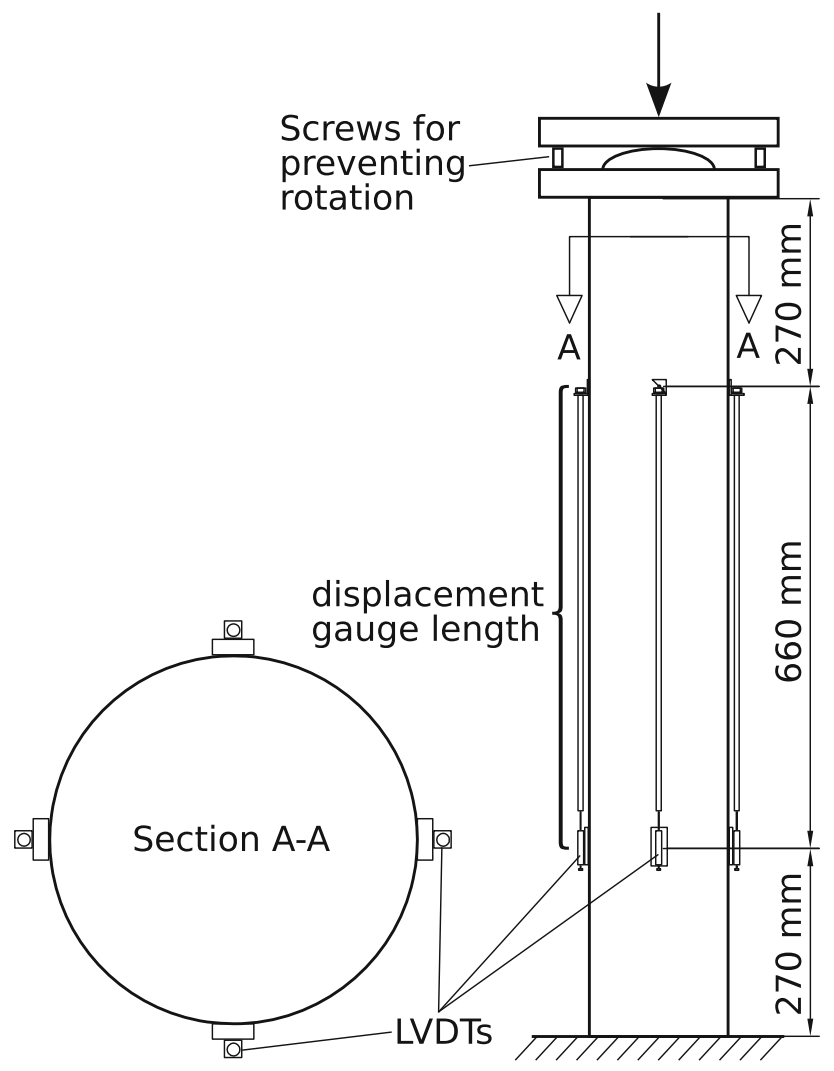

Fig. 7 Test scheme of axial pile compression tests with a gauge length of $660 \mathrm{~mm}$

\section{Test results for small clear specimens}

\subsection{Data and observations}

The failure of the rather stout, small clear DIN specimens occurred for both the dry and wet specimens throughout via the well-known inclined kink band formation damage (Roš 1936; Hoffmeyer 1990). In the case of the wet specimens, the kink bands were wider. The load compression deformation curves were linear until approx. $80 \%$ of peak load. After peak load, the stress dropped about $20 \%$ before reaching a pronounced post-peak plateau in many cases. The green specimens could be tested to a much higher strain (often $30 \%$ and more as determined from global displacement) than the dry specimens before total failure. In the case of the more slender EN 408 compression specimens, the failure occurred partly as pure kink band formation, however for about $40 \%$ of the specimens the kink band formation was overlaid by lateral bending associated with large (several $\mathrm{mm}$ ) deformations perpendicular to the loading axis. Figure 9 shows the lognormal distributions of the compressive strengths of the dry and wet DIN and EN specimens, respectively. Table 2 contains the statistical evaluation of all test series regarding
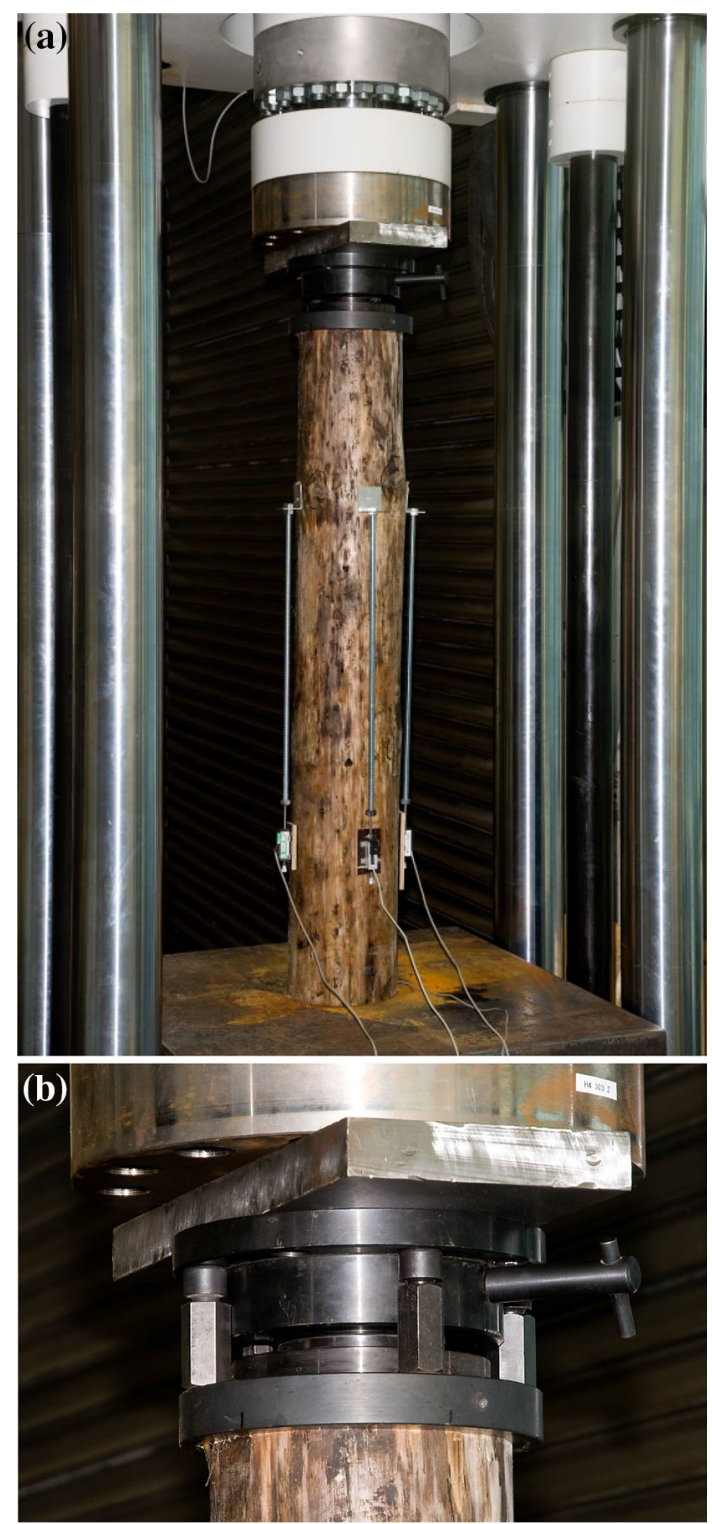

Fig. 8 View of realized axial compression test set-up. a Total view of test set-up. b Loading detail at upper pile end; spherical compression hinge with screws for rotation blocking

compressive strengths, densities and moisture contents. Further, ratios $f_{c, 0, E N} / f_{c, 0, D I N}$ for the dry and green moisture state are given to reveal the influence of the different specimen aspect ratios.

The density results reveal that all test series had a closely conforming density distribution characterized by an average density $\rho_{12}$ of about $440 \mathrm{~kg} / \mathrm{m}^{3}$ and $5 \%$-quantile values in the range of about 330 to $350 \mathrm{~kg} / \mathrm{m}^{3}$. The compressive strength ratios $f_{c, 0, E N} / f_{c, 0, D I N}$ reveal on average (dry and wet, $x_{\text {mean }}$ and $x_{05}$-level) roughly $5 \%$ lower strengths for the EN specimen shape. This reflects the superimposed bending and buckling effects of the more slender EN specimens. For both specimen types (DIN, EN) 
the mean compressive strength of the specimens that were taken from the inner part of the cross-sections was $83 \%$ of the compressive strength of the outer specimens.

\subsection{Evaluation of moisture impact}

Figure 10 and the related regression equation

$f_{c, 0, u=12 \%}=4.72+1.83 \cdot f_{c, 0, \text { green }}$

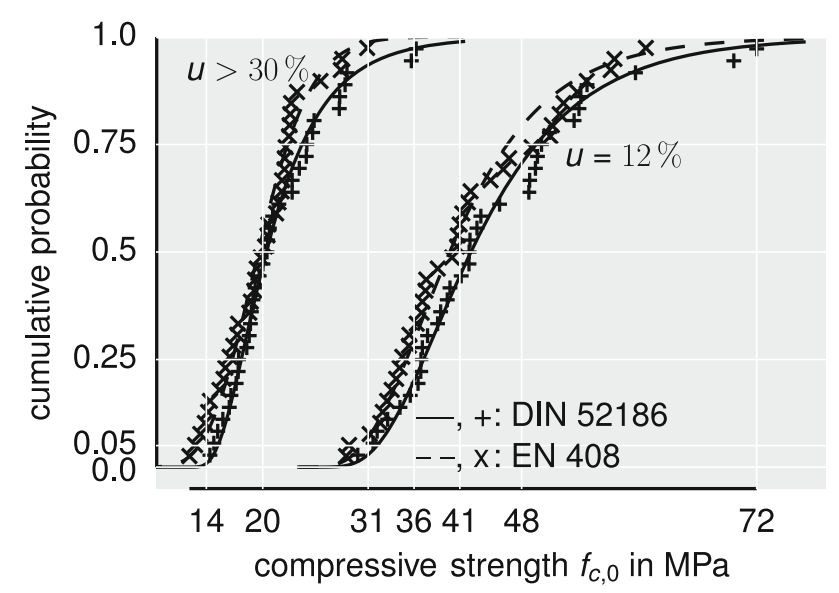

Fig. 9 Cumulative distributions of compressive strength parallel to the fiber of matched small defect free spruce specimens according to DIN 52185 (1976) and EN 408 (2010) tested in dry (MC $\approx 14 \%$ and adjusted to $\mathrm{MC}=12 \%)$ and water saturated state $(\mathrm{MC} \approx 200 \%)$ reveal a highly correlated $\left(R^{2}=0.97\right)$ relationship of the compressive strength parallel to the fiber of the very closely matched water saturated (green) and dry DIN specimens. The strength data for the dry state $(u=12 \%)$ presented in Fig. 10, Eq. (9) and Table 2 were transformed from the experimentally obtained strength values with consideration of the moisture content of every single specimen $\left(u_{\text {mean }, d r y}=14 \%\right.$ ) by Eq. (8b). The relationship for the originally obtained test data $f_{c, 0, u=14 \%}=4.45+$ $1.64 \cdot f_{c, 0, \text { green }}$ delivers about $10 \%$ lower values than Eq. (9). This result coincides well with those obtained from the relationship $f_{c, 0,12} / f_{c, 0, u}=20 /(32-u[\%])$ specified in Kollmann (1955) for compressive strength adjustment of clear spruce/fir in the moisture range of 8 to $18 \%$.

The revealed high correlation of $f_{c, 0, g \text { reen }}$ and $f_{c, 0, u=12 \%}$ of the almost defect free specimens suggests that the strength decreasing influence of the high moisture content is rather unaffected by the density of the timber. This is substantiated by a regression of the strength ratio $f_{c, 0, \text { green }} / f_{c, 0,12}$ vs. density $\rho_{12}$ which gives no $\left(R^{2}=0.2\right)$ correlation (Note: the EN 408 specimens revealed a slightly different relationship of $f_{c, 0, u=12 \%}=9.32+$ $1.14 f_{c, 0, \text { green }}$ with a considerably worse coefficient of correlation of $R^{2}=0.67$, which is presumably due to the less closely matched specimens).

Table 3 specifies the ratio $f_{c, 0, \text { green }} / f_{c, 0,12}$ at the mean, $5 \%$-quantile and minimum strength level. The results for the DIN and EN specimens conformed closely. On average,

Table 2 Compilation of results for matched small clear spruce specimens tested in compression parallel to the fiber in dry and green state according to two different test standards (DIN 52185 and DIN EN 408)

\begin{tabular}{|c|c|c|c|c|c|}
\hline \multirow[t]{4}{*}{ Physical, mechanical property or ratio } & \multirow[t]{4}{*}{ Statistical quantity } & \multicolumn{4}{|c|}{ Small scale clear wood specimens } \\
\hline & & \multicolumn{2}{|c|}{ Dry $(\mathrm{MC}=12 \%)$} & \multicolumn{2}{|c|}{ Green $(\mathrm{MC}>30 \%)$} \\
\hline & & \multicolumn{2}{|c|}{ Specimen type } & \multicolumn{2}{|c|}{ Specimen type } \\
\hline & & DIN 52185 & EN 408 & DIN 52185 & EN 408 \\
\hline No. of specimens tested & & 42 & 42 & 42 & 42 \\
\hline No. of specimens used for evaluation & & 35 & 38 & 35 & 38 \\
\hline Moisture content in $\%$ & $x_{\text {mean }}(\mathrm{COV}$ in $\%)$ & $13.9(1.9)$ & $13.9(2.5)$ & $200(16)$ & $181(18)$ \\
\hline \multirow[t]{5}{*}{ Compressive strength $f_{c, 0}$ in $\mathrm{MPa}$} & $x_{\text {mean }}(\mathrm{std})$ & $44.3(9.9)$ & $41.6(8.5)$ & $21.9(5.4)$ & $20.1(4.4)$ \\
\hline & $\mathrm{COV}$ in $\%$ & 22.4 & 20.3 & 24.7 & 22.0 \\
\hline & $x_{\min }$ & 30.2 & 29.0 & 14.6 & 12.5 \\
\hline & $x_{\max }$ & 72.4 & 60.7 & 36.4 & 31.2 \\
\hline & $x_{05}$ & 29.3 & 28.4 & 13.9 & 13.0 \\
\hline \multirow[t]{5}{*}{ Density $\rho_{12}$ in $\mathrm{kg} / \mathrm{m}^{3}$} & $x_{\text {mean }}(\mathrm{std})$ & $442(75)$ & $442(58)$ & 439 (64) & $442(60)$ \\
\hline & $\mathrm{COV}$ in $\%$ & 16.9 & 13.0 & 14.7 & 13.6 \\
\hline & $x_{\min }$ & 349 & 334 & 353 & 348 \\
\hline & $x_{\max }$ & 653 & 580 & 659 & 604 \\
\hline & $x_{05}$ & 326 & 347 & 337 & 344 \\
\hline Compressive strength ratio & at $x_{\text {mean }}$ level & 0.94 & & 0.95 & \\
\hline$f_{c, 0, E N} / f_{c, 0, D I N}$ & at $x_{05}$ level & 0.97 & & 0.94 & \\
\hline
\end{tabular}




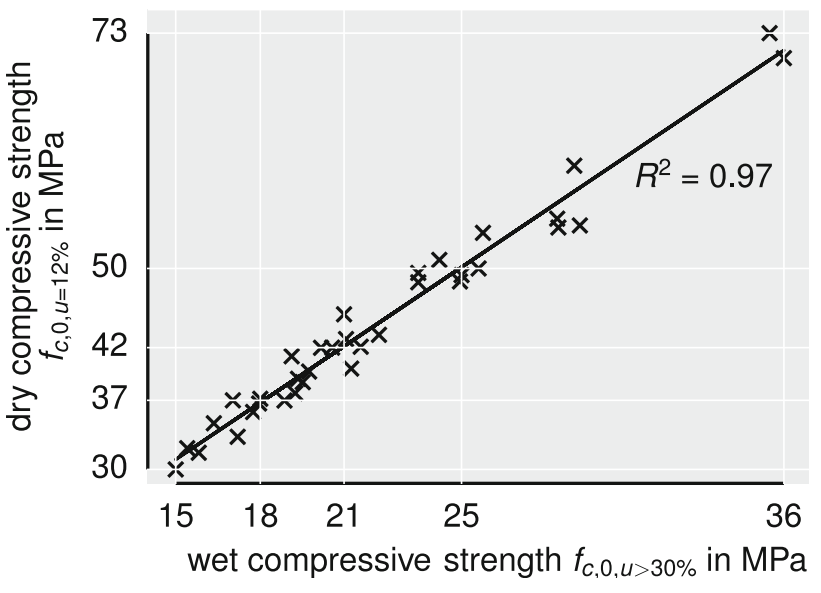

Fig. 10 Correlation of compressive strength parallel to the fiber of matched clear wood spruce specimens according to DIN 52185 tested at $u=12 \%$ and in the green/fully water saturated state

Table 3 Ratios of compressive strength and modulus of elasticity parallel to the fiber at water saturated green state $(u>30 \%)$ vs. dry state $(u=12 \%)$ of small defect free and structural sized pile/round wood specimens

\begin{tabular}{|c|c|c|c|c|c|}
\hline \multirow[t]{3}{*}{ Specimen size } & \multirow[t]{3}{*}{ Specimen type } & \multicolumn{4}{|c|}{ MOR and MOE ratios } \\
\hline & & \multicolumn{3}{|c|}{$k_{\text {moist }, \text { green }}=\frac{f_{c, 0, \text { green }}}{f_{c, 0, d r y}}$} & \multirow{2}{*}{$\begin{array}{l}\frac{E_{c, 0, \text { greer }}}{E_{c, 0, \text { dry }}} \\
x_{\text {mean }}\end{array}$} \\
\hline & & $x_{\text {mean }}$ & $x_{05}$ & $x_{\min }$ & \\
\hline \multirow[t]{2}{*}{ Small defect free } & DIN 52185 & 0.49 & 0.47 & 0.48 & - \\
\hline & EN 408 & 0.48 & 0.46 & 0.43 & - \\
\hline Structural sized & Round wood & 0.57 & 0.66 & 0.60 & 0.89 \\
\hline
\end{tabular}

$k_{\text {moist,green }}$-values of about 0.48 were obtained at the $x_{\text {mean }}{ }^{-}$ and $x_{05}$-level. The obtained mean moisture modification factors are about $10 \%$ lower as compared to the literature evaluation (Eq. 8b), though agree well, when considering higher moisture contents of $u=50 \%$ or higher.

\section{Test results for the pile specimens}

\subsection{Data and observations}

The load displacement behavior of the dry pile specimens was strictly linear up to about 85 to $90 \%$ of the maximum compression load $F_{c, 0, \max }$, whereas for the wet specimens, the linear range ended somewhat lower at about 75 to $85 \%$ of $F_{c, 0, \max }$. Beyond the linear stiffness region, progressive nonlinearity occurred throughout until peak load. For both dry and wet specimens, stable strain softening with gradually decreasing load occurred after peak load. In the case of the wet specimens, the quasi plastic peak load plateau was more expressed and the slope of the compressive stress-strain curves on the descending branch was not as
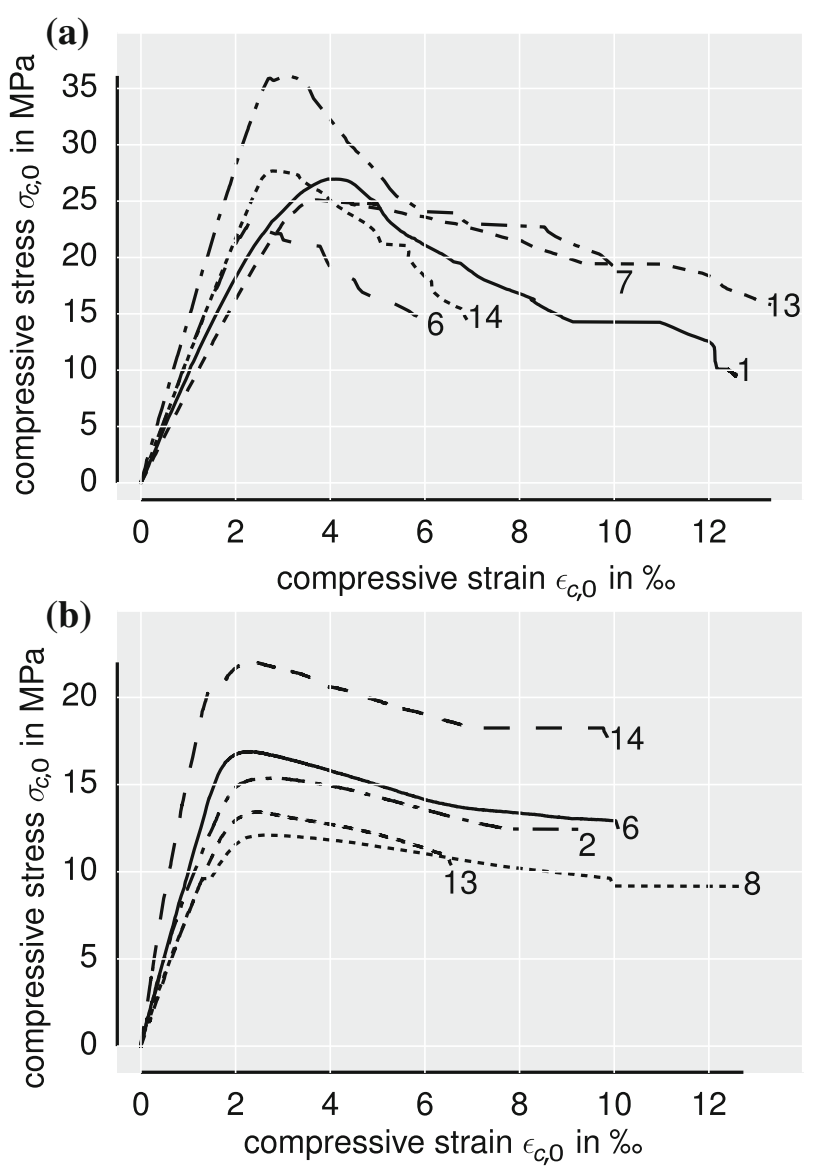

Fig. 11 Compressive stress-strain curves in axial compression tests with structural sized round wood specimens (strains are means from four LVDTs (see Fig. 7). a Dry piles. b Wet piles

steep. Figure $11 \mathrm{a}$ and $\mathrm{b}$ show typical stress-strain curves encountered for the dry and wet specimens, respectively.

The failure of the pile specimens showed in principle similar features for the case of the dry and wet logs, however the ductility of the local and global failure mechanisms was far more expressed in the case of the wet specimens. In general, three different failure mechanisms occurred in a successive manner, first in the nonlinear prepeak range and then in the softening post-peak domain, being (1) splitting parallel to the fiber axis starting often but not generally at a knot, (2) kink band formation as in the case of the small clear specimens and (3) localized buckling of a larger stem part at the periphery. Figures 12 and 13 show examples of the observed failures.

Figure 14 gives the compressive strength results of the individual dry and wet pile specimens as cumulative frequencies together with the fitted lognormal distribution functions. The strength values were derived from peak load and pile diameters at failure plane. Table 4 presents the statistical evaluation of the experimental data regarding compressive strength, modulus of elasticity and density. 


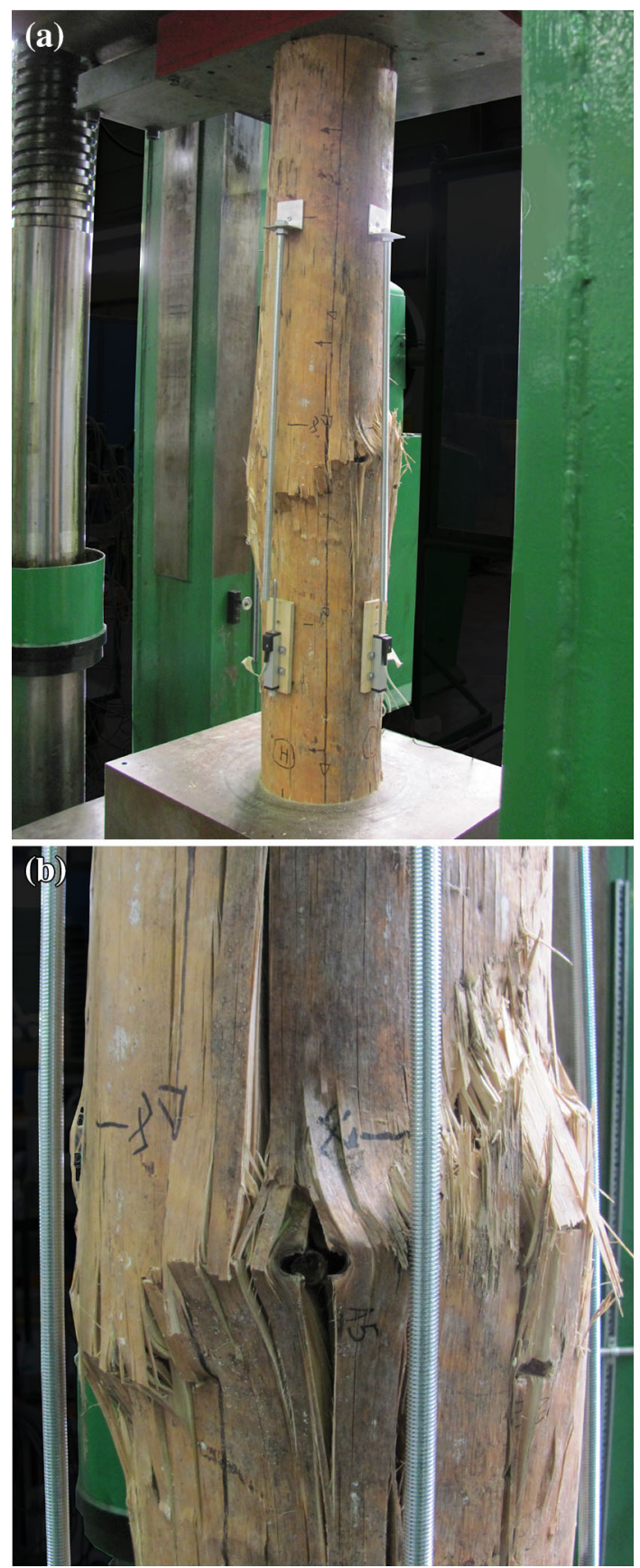

Fig. 12 Failure appearances of dry pile specimens loaded in axial compression. a Total view of failed specimen.b Details of kink band and local buckling

Similarly, as in the case of the small clear specimens, the densities of the dry and wet pile specimens due to the performed matching procedure conform closely. The average densities $\rho_{12}$ of the dry and wet sample are 453 and $447 \mathrm{~kg} / \mathrm{m}^{3}$, respectively, and fit very well with the density results of the clear wood specimens, especially when the correction factor of (1/1.05) according to EN 384 (2010) accounting for the density contribution of the knots is applied to the stem specimens.
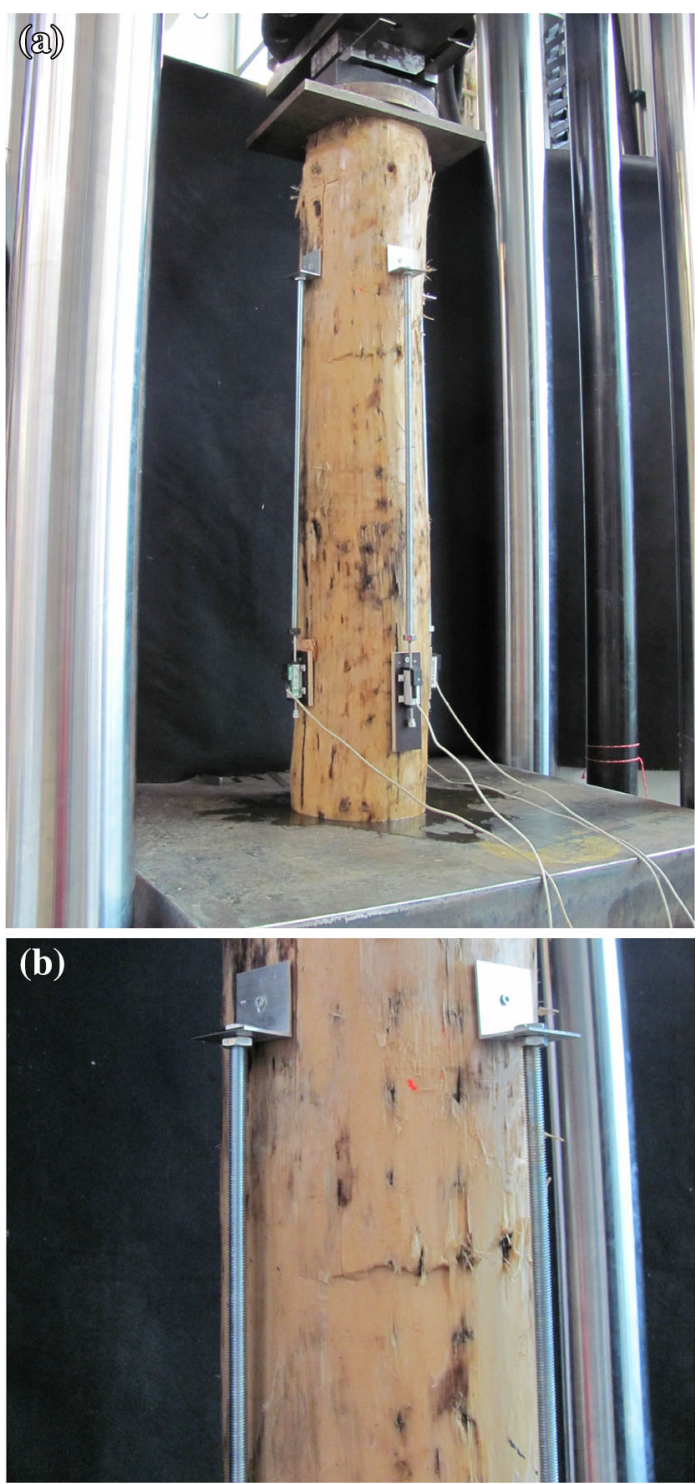

Fig. 13 Failure appearances of wet (water saturated) pile specimens loaded in axial compression. (a) Total view of failed specimen. (b) Details of kink band and local buckling

The values obtained for the $5 \%$ quantile of compressive strength, mean modulus of elasticity and characteristic density of the dry round wood specimens $f_{c, 0,05}=21.5 \mathrm{MPa}, E_{c, 0, \text { mean }}=12.1 \mathrm{GPa}$ and $\rho_{12,05}=$ $350 \mathrm{~kg} / \mathrm{m}^{3}$ conform very well with the numbers specified for strength class $\mathrm{C} 24$ of the European strength class standard EN 338 (2010) for structural timber, which designates values of $f_{c, 0, k}=21 \mathrm{MPa}, E_{0, \text { mean }}=11 \mathrm{GPa}$, $\rho_{\text {mean }}=420 \mathrm{~kg} / \mathrm{m}^{3}$ and $\rho_{k}=350 \mathrm{~kg} / \mathrm{m}^{3}$ (Note: The standardized values refer implicitly to sawn timber with rectangular cross-sections; for round wood no European strength class standard exists). 


\subsection{Evaluation of moisture impact}

The ratios of compressive strength and MOE of wet $(u>30 \%)$ vs. dry $(u=12 \%)$ state are given in Table 3 for relevant statistical levels (MOE: $x_{\text {mean }}$ only). The moisture modification factor at the mean strength level

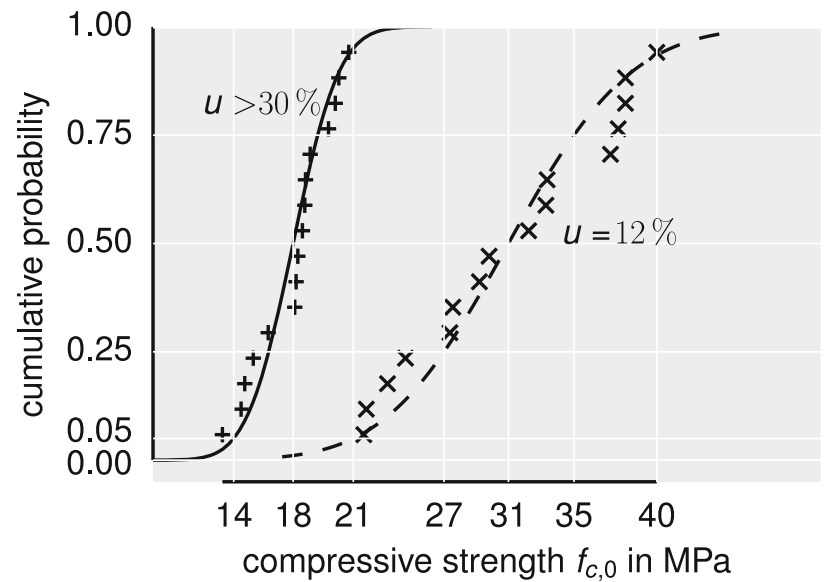

Fig. 14 Compressive strength results of the individual dry and wet round wood specimens as cumulative frequencies together with the fitted lognormal distribution functions $k_{\text {moist }, \text { mean,green }}=\frac{f_{c, 0, \text { mean, green }}}{f_{c, 0, \text { dry }, \text { mean }}}=0.57$

is roughly $15 \%$ higher as compared to the clear wood samples. The higher $k_{\text {moist,mean,green }}$ possibly results from the lower moisture content of the wet specimens that just reaches $30 \%$ in the inner cross-sections of most wet piles, see Sect. 4.1. Since strength reductions over $30 \%$ moisture content are debatable and against the contemporary technical understanding, the results will not be adjusted in the following.

It should be kept in mind, however, that even higher reduction factors could result from future research.

In contrast to the small clear specimens, where the strength ratios of wet to dry specimens were rather similar at different statistical distribution levels, the ratio at the lower tail of the distributions is now considerably higher, i.e.

$k_{\text {moist }, 05, \text { green }}=\frac{f_{c, 0,05, \text { reen }}}{f_{c, 0,05, \text { dry }}}=0.66$.

The mathematical explanation for the increased value for $k_{\text {moist }, 05, \text { green }}$ is related to a considerably lower COV of $13.1 \%$ of the wet pile specimens as compared to a $\mathrm{COV}=19.8 \%$ of the dry pile specimens. This is in
Table 4 Statistical evaluation of test results MOR, MOE and density of structural sized spruce pile specimens tested in axial compression at dry and wet (water saturated) state

\begin{tabular}{|c|c|c|c|c|}
\hline \multirow[t]{2}{*}{ Physical, mechanical property or ratio } & \multirow[t]{2}{*}{ Statistical quantity } & \multicolumn{2}{|c|}{ Moisture state of specimen } & \multirow{2}{*}{$\begin{array}{l}\text { Ratio } \\
\text { Wet/dry }\end{array}$} \\
\hline & & Dry & Wet & \\
\hline \multicolumn{2}{|l|}{ No. of specimens tested } & 17 & 17 & \multirow[t]{4}{*}{17} \\
\hline Moisture content in $\%$ & $x_{\text {mean }}$ & 12.5 & 89.4 & \\
\hline Pile diameter at failure plane $d_{f}$ in $\mathrm{mm}$ & $x_{\text {mean }}$ & 214 & 196 & \\
\hline Bottom/top diameter $d_{\text {bottom,top }}$ in $\mathrm{mm}$ & $x_{\text {mean }}$ & $220 / 205$ & $204 / 190$ & \\
\hline \multirow[t]{6}{*}{ Compressive strength $f_{c, 0}$ in $\mathrm{MPa}^{\mathrm{a}}$} & $x_{\text {mean }}$ & 30.8 & 17.6 & \multirow[t]{2}{*}{0.57} \\
\hline & $\operatorname{std}(\mathrm{x})$ & 6.1 & 2.3 & \\
\hline & $\mathrm{COV}$ in $\%$ & 19.8 & 13.1 & 0.66 \\
\hline & $x_{05}$ & 20.3 & 13.4 & 0.66 \\
\hline & $x_{\min }$ & 21.9 & 13.3 & 0.60 \\
\hline & $x_{\max }$ & 39.9 & 21.0 & 0.53 \\
\hline \multirow[t]{5}{*}{ Density $\rho_{12}$ in $\mathrm{kg} / \mathrm{m}^{3}$} & $x_{\text {mean }}$ & $453(48)$ & $447(34)$ & 0.99 \\
\hline & $\mathrm{COV}$ in $\%$ & 10.6 & 7.5 & 0.71 \\
\hline & $x_{\min }$ & 398 & 389 & 0.98 \\
\hline & $x_{\max }$ & 566 & 550 & 0.97 \\
\hline & $x_{05}$ & 370 & 387 & 1.05 \\
\hline \multirow[t]{6}{*}{$\operatorname{MOE} E_{c, 0}{ }^{\mathrm{a}}$ in $\mathrm{GPa}$} & $x_{\text {mean }}$ & 12.1 & 10.7 & \multirow[t]{2}{*}{0.89} \\
\hline & $\operatorname{std}(x)$ & 1.9 & 1.6 & \\
\hline & $\mathrm{COV}$ in $\%$ & 15.9 & 14.9 & 0.93 \\
\hline & $x_{05}$ & 8.6 & 7.9 & 0.92 \\
\hline & $x_{\min }$ & 8.9 & 7.7 & 0.87 \\
\hline & $x_{\max }$ & 15.0 & 14.3 & 0.95 \\
\hline
\end{tabular}

${ }^{a}$ Dry values adjusted from experimental $\mathrm{MC}$ to $\mathrm{MC}=12 \%$ by provisions given in EN 384 (2010), i.e. $3 \%$ and $1 \%$ change per $1 \% \mathrm{MC}$ change in case of MOR and MOE, respectively 
contrast to the small clear specimens where the wet specimens gave on average about $12 \%$ higher COVs. One possible reason for the reduced scatter of structural sized round wood/pile specimens in wet state as compared to dry conditions and the hereof resulting increase of ratio $f_{c, 0, \text { green }} / f_{c, 0, d r y}$ at the $x_{05}$-level might be that the tree branches allow for a better distribution of the stresses, especially in the fully water saturated material state, leading to a more homogeneously behaving branch-reinforced bulk composite. Although the higher strength ratios at the $x_{05}$ and $x_{\min }$ level seem plausible, there remains the uncertainty that the reason is primarily statistical due to the limited number of specimens.

With regard to modulus of elasticity, the moisture bound decrease obtained at the mean level (see Table 3) was

$\frac{E_{c, 0, \text { mean, }, \text { reen }}}{E_{c, 0, \text { dry, mean }}}=0.89$

and on the $x_{05}$ and $x_{\min }$ level very similar ratios of 0.90 and 0.87 , respectively, were determined. The results conform closely to data by Kühne et al. (1955) and Fischer (1960) on the moisture-MOE relationship of spruce and fir in compression parallel to fiber resulting in a similar ratio of 0.89 at the mean level. Finally, it can be stated that the experimentally obtained ratios of compressive strength parallel to the fiber and MOE for water saturated vs. dry structural sized coniferous (European spruce) pile specimens comply well with respective adjustment factors specified in the North American standards and design provisions for round wood piles.

\section{Conclusion}

The conducted work confirmed that a moisture modification factor of 0.8 as specified implicitly in the current Eurocode 5 for service class 3 conditions is too little of a reduction for the compression strength parallel to the fiber of spruce and fir in the very wet, fiber saturated state. The test results for clear wood-together with a comprehensive literature evaluation-gave a moisture reduction factor in the range of 0.5 to 0.55 at the mean strength level. The investigations with well matched wet and dry structural sized pile specimens revealed a somewhat less pronounced strength decrease of about $35 \%$ vs. the dry state $(\mathrm{MC}=12 \%)$ on the $5 \%$ quantile level. Hence, for design of wet, water saturated piles and sawn softwood lumber, a pure moisture modification factor of $k_{\text {moist,green }}=0.65$ seems appropriate.

The superimposed impact of moisture and loading time on strength is considered in several design codes productwise. Based on the time effect for permanent duration of load, which can be derived from Eurocode 5 as $k_{\text {time }}=0.6$, at present irrespective of moisture level, a modification factor $k_{\text {mod }}=0.65 \cdot 0.6=0.4$ would result for lumber and piles subjected to permanent duration of load in the water saturated state. A value of this order of magnitude is proposed as a safe adjustment factor for a revised version of Eurocode 5. A more moderate value of $k_{\text {mod }}$ in the range of 0.5 might be justifiable if proven by adequate experimental and theoretical approaches i.a. including FORM/SORM (First/Second Order Reliability Method) calibration.

Although the above is derivation-wise rigorously confined to European spruce and fir, it may be assumed to hold for other softwood species like larch and Douglas fir as well. In the case of modulus of elasticity of fiber saturated clear and structural sized softwood timbers loaded in compression parallel to fiber, a reduction factor of 0.85 is recommended.

Open Access This article is distributed under the terms of the Creative Commons Attribution 4.0 International License (http:// creativecommons.org/licenses/by/4.0/), which permits unrestricted use, distribution, and reproduction in any medium, provided you give appropriate credit to the original author(s) and the source, provide a link to the Creative Commons license, and indicate if changes were made.

\section{References}

ANSI/AWC NDS-2015 (2015) National design specification (NDS) for wood construction 2015 edition. American National Standards Institute (ANSI), Washington, D.C., USA and American Wood Council (AWC), Leesburg, VA, USA

ASTM D2555-06 (Reapproved 2011) (2011) Standard practice for establishing clear wood strength values. ASTM International, West Conshohocken, PA, USA

ASTM D2899-12 (2012) Standard practice for establishing allowable stresses for round timber piles. ASTM International, West Conshohocken, PA, USA

ASTM D3200-74 (Reapproved 2012) (2012) Standard specification and test method for establishing recommended design stresses for round timber construction poles. ASTM International, West Conshohocken, PA, USA

Austrian Institute of Construction Engineering (OiB) (2013a) VIGAM-Glued laminated timber of oak. ETA-13/0642 European Technical Approval, valid until 27.06.2018

Austrian Institute of Construction Engineering (OiB) (2013b) Sierolam - Glued laminated timber of chestnut. ETA-13/0646 European Technical approval, valid until 27.06.2018

Buiten H, Rijsdijk JF (1982) Compressive strength of larch, douglas fir and spruce piles (in dutch). Rapport HI 82.1140, Houtinstituut TNO, Postbus 151, 2600 AD Delft, order Nr.: 30.01.1.0002

CSA O86-09 (2009) Engineering design in wood. Canadian Standards Association (CSA), Toronto, ON, Canada

DIN 1052-1 (1988) Timber structures; design and construction. German Institute for Standardization (DIN), Berlin, Germany

DIN 4074-2 (1958) Building timber for wood building components; quality conditions for building logs (softwood). German Institute for Standardization (DIN), Berlin, Germany

DIN 52185 (1976) Testing of wood; compression test parallel to grain. German Institute for Standardization (DIN), Berlin, Germany 
EN 14358 (2007) Timber structures-calculation of characteristic 5-percentile values and acceptance criteria for a sample. European Committee for Standardization (CEN), Brussels, Belgium

EN 1995-1-1 (2010) +AC (2006)+A1 (2008) Eurocode 5: design of timber structures-part 1-1: General-common rules and rules for buildings. European Committee for Standardization (CEN), Brussels, Belgium

EN 338 (2010) Structural timber-strength classes. European Committee for Standardization (CEN), Brussels, Belgium

EN 384 (2010) Structural timber-Determination of characteristic values of mechanical properties and density state. European Committee for Standardization (CEN), Brussels, Belgium

EN 408 (2010)+A1 (2012) Timber structures—structural timber and glued laminated timber-determination of some physical and mechanical properties. European Committee for Standardization (CEN), Brussels, Belgium

Fischer H, Kühne H (1960) Buckling strength of swiss spruce, fir, larch, red beech and oak (in German). Bericht 190, EMPA

Frese M, Enders-Comberg M, Blaß HJ, Glos P (2011) Strength of spruce glulam subjected to longitudinal compression. International Council for Research and Innovation in Building and Construction, Working Commission W18-Timber Structures, Alghero, Italy, paper 44-12-2

Glass SV, Zelinka SL (2010) Wood handbook-wood as an engineering material (2010 Edition), Forest Products Society, Madison, Wisconsin, USA, chap Moisture relations and physical properties of wood, pp 4-1-4-19

Glos P (1978) Determination of the strength behavior of glulam under compressive stress from material and action parameters (in German). PhD thesis, Technische Universität München, Fachbereich Bauingenieur-und Vermessungswesen

Hoffmeyer P (1990) Failure of wood as influenced by moisture and duration of load. PhD thesis, State University of New York, College of environmental Science and Forestry

ISO 20152-1 (2010) Timber structures-bond performance of adhesives-part 1:basic requirements. International Organization for Standardization (ISO), Geneva, Switzerland
Jorissen A (2007) Module 7: the strength of foundation piles (in dutch). In: SHR Course Timber Research during Foundation Inspections. SHR Timber Research Wageningen, The Netherlands

Kollmann F (1955) Technology of wood and wood-based materials. Springer, Berlin, Germany

Kühne H, Fischer H, Vodoz J, Wagner T (1955) Influence of water content, bulk density, fiber position and tree ring position on the strength and ductility of swiss spruce, fir, larch, red beech and oak (in German). Report 183, Swiss Federal Laboratories for Materials Science and Technology (EMPA), Zurich, Switzerland

NEN 5491 (1999) Quality requirements for timber-piles-coniferous timber. Netherlands Standardisation Institute (NEN), Delft, Netherlands

NEN 6760 (2008) TGB 1990_timber structures-basic requirements and determination methods. Netherlands Standardisation Institute (NEN), Delft, Netherlands

NEN-EN 1990+A1+A1/C2 (2011) Eurocode: basis of structural design. Netherlands Standardisation Institute (NEN), Delft, Netherlands

NEN-EN 1995-1-1 NB (2011) National annex to NEN-EN 1995-1-1. Eurocode 5: design of timber structures-part 1-1: Generalcommon rules and rules for buildings (includes $\mathrm{C} 1: 2006$ and A1:2008). Netherlands Standardisation Institute (NEN), Delft, Netherlands

NZS 3603 (1993) Timber structures standard. Amendments No 1 \& 2 \& 4 Appended. Standards New Zealand, Wellington, New Zealand

Roš M (1936) Wood as a building material (in German). 1. Schweiz. Kongress zur Förderung der Holzverwertung, Bern, Switzerland

RVR (2015) Framework agreement for lumber trade in Germany (RVR) (in German). German Forestry Council (DFWR) and German Wood Council (DHWR), Berlin, Germany

van de Kuilen JWG (1994) Determination of the characteristic compressive strength of timber piles. TNO-report 94-CONR0271, TNO 